Please send trade news information and illustrations to Arveen Bajaj at the $B D J$, Nature Publishing Group, The Macmillan Building, 4-6 Crinan Street, London N1 9XW.

Trade news is provided as a service to readers using text and images from the manufacturer, supplier or distributor and does not imply endorsement by the BDJ. Normal and prudent research should be exercised before purchase or use of any product mentioned.

\section{Practice management made easy}

DentalPlus is an all-new piece of practice management software designed by software experts V3FM, with direct input from dentists, nurses and receptionists. This innovative software is fully web enabled, supporting local inhouse systems, multi-site practices, external secure access or even hosted systems.

DentalPlus enables direct download/ installation of both original software and updates, with instant access and user contact via websites, email, SMS and VoIP. The programme manages not only your clinical appointments, charting, treatment plans and financial aspects, but also the whole practice with a diary, directory, clinical audit and CPD logging. NHS practices will also benefit from the real time UDA monitor. In addition, simple inclusive pricing and loyalty bonuses bring maximum cashflow benefit.

With FREE updates, a FREE website, FREE help and FREE data conversion, check out DentalPlus today. For more information contact DentalPlus on 08450521244 or visit www.dentalplus.co.uk. Reader response number $\mathbf{5 1}$

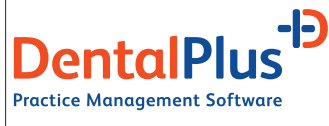

\section{Excellence in cross infection control}

The Alkapharm group of companies specialise exclusively in products and services to help in the fight against bactericidal cross infection. Alkapharm's new website now enables visitors to view and download comprehensive product information and safety data. Dental surgeries can download and print their very own practice guide to cross infection, entitled 'Quality and Excellence in the Control of Cross Infection: A Guide for the General Dental Practice.' The manual can easily be adapted to individual practice requirements. To download your FREE copy, visit www.alkapharm.co.uk.

Reader response number 52

\section{TRADE NEWS \\ WHAT'S NEW}

\section{Advanced adhesive technology}

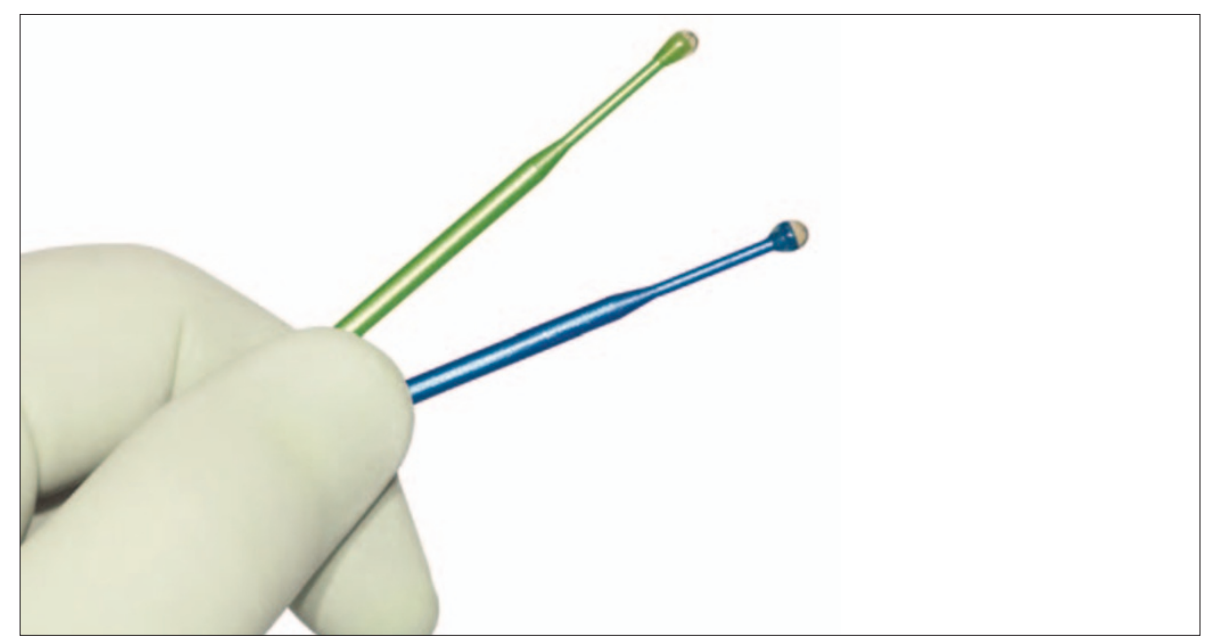

New disposable placement instruments featuring advanced technology in adhesive coating have been announced by MICROBRUSH ${ }^{\circledR}$ INTERNATIONAL. Designed to securely hold and place fragile or small items during restorative treatment, micro-Stix ${ }^{\mathrm{TM}}$ use the latest technology in adhesive coating to create a practical handle for veneers, crowns, inlays, brackets and numerous other objects. The micro-Stix ${ }^{\mathrm{TM}}$ design consists of flexible plastic sticks with patented bendable necks and non-hardening adhesive tips that securely attach to most surfaces. They are available in two different holding strengths - Smart Hold and Original. Smart Hold micro-Stix ${ }^{\mathrm{TM}}$ are the only adhesive-tip applicators on the market to feature pressure sensitive adhesive.

This advanced adhesive lets practitioners determine the holding strength by the force exerted on the applicator's tip - less pressure for placing delicate items with easier release, or more pressure for larger items. Original hold features the strongest adhesive for extra holding strength. The standard package contains 64 micro-Stix $^{\mathrm{TM}}$ in four clear plastic cases of 16 applicators each.

For more information or a free sample please call MICROBRUSH ${ }^{\circledR}$ INTERNATIONAL on +12623754011 or visit www.microbrush.com.

Reader response number 50

\section{Revolutionary rubber dam}

KerrHawe have developed a revolutionary new design of rubber dam. As all dentists will know, placing a rubber dam can be tricky for the operator and rather uncomfortable for the patient. The new OptiDam simplifies placement and your patients will hardly notice it's there!

The three-dimensional shape of OptiDam and the anatomical frame shape match the contours of the mouth, allowing greater access for the dentist and improved visibility to the working area thanks to the low tension. The patient will be able to breathe normally and will appreciate the greater comfort. OptiDam also has a unique nipple design that reduces preparatory time and work. Instead of marking the tooth position on the dam and hole punching, OptiDam allows you to simply cut off the nipple that corresponds to the tooth you will be working on.

OptiDam is available in anterior or posterior universal sizes that fit all. For further information contact KerrHawe on 01733892292.

Reader response number 53

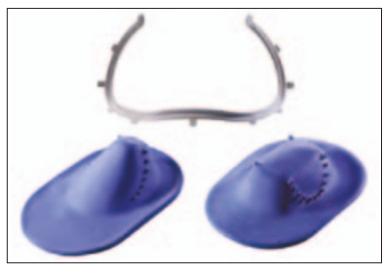



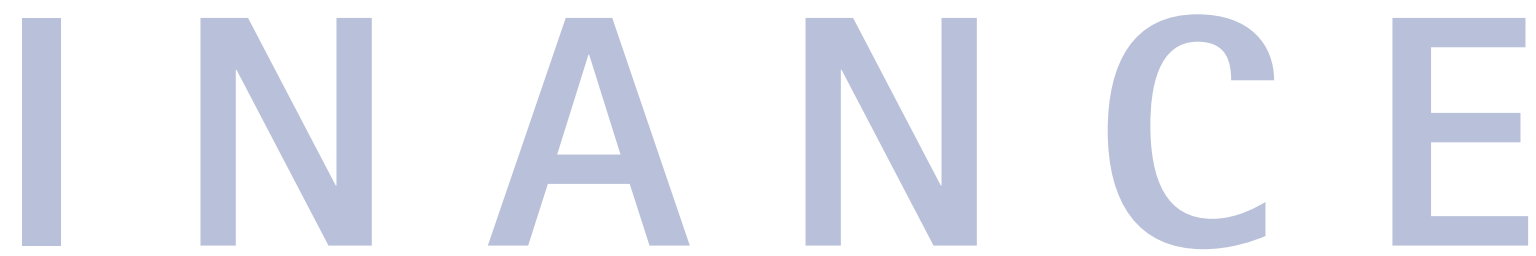

\section{0\% from Braemar} Finance

Braemar Finance is delighted to announce that Scottish-based organisation IndepenDent Care Plans UK Ltd has selected Braemar Finance to be the preferred supplier of '0\% Patient Finance Solution'. Exclusive to members of the IndepenDent Care Plans UK Ltd network, Braemar Finance is able to offer $0 \%$ finance, or interest free loans, to dental patients for amounts from $£ 400$ to $£ 25,000$ to fund any type of dental treatment or programme of treatments.

Patients are able to apply for the loans through the dental practice using a dedicated customer helpline or by email. Applications will be dealt with quickly and funds released promptly, enabling dentists to start the treatment almost immediately. Patients can borrow exactly the amount needed to cover their treatment plan and repayments are set up by direct debit over a time period that suits them. There is very little administration required, and Braemar has set up internal resources and support for both dentists and patients should any queries arise.

Dentists interested in offering this new service to their patients should contact David Foster at Braemar Finance on 01563 852100 for more information on how to get started. Alternatively, information is also available from IndepenDent Care Plans UK Ltd on 01463222999.

Reader response number 54

\section{D $\overline{\text { FINANCE }}$}

\section{Independent advice for dentists}

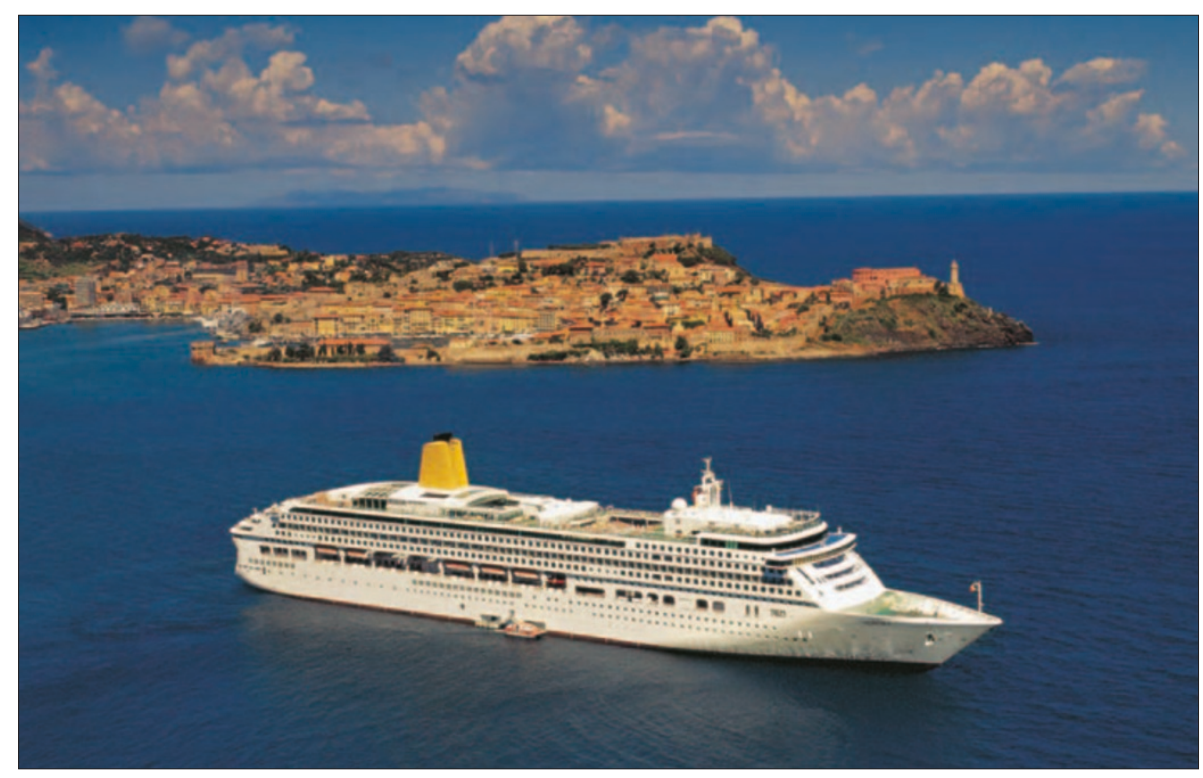

With experience and knowledge of the ever-changing financial world, from investment, saving and retirement to the mortgage market, money4dentists is able to help dentists reduce their monthly outgoings by negotiating the lowest interest rates available for both residential and practice finance.

A specialist firm of independent financial advisers (IFAs) who work with dentists at all stages of their careers, money4dentists help maximise investment returns with the aim of showing dentists how to become financially independent and achieve financial goals in all aspects of life, from financial protection for families to inheritance tax planning.

Named the 2005 Mortgage IFA of the year, money4dentists is pleased to be exhibiting at this year's BDA conference in May. Advisers will be available on the stand to offer guidance on mortgages and will be able to advise on the best deals around using constantly updated information from the whole mortgage market. There will also be the opportunity to enter a competition to win a two night cruise for two to Bruges aboard the P\&O liner Aurora!

Whatever your financial questions, money4dentists will be able to help you answer them and ensure that you have the best possible deals available to you. For further information call 08453455060 or visit stand 69 at the conference.

Reader response number 55 


\section{Up front patient loans}

3dee patient loans now overcome the two most important factors that can affect practice success: patients deterred from treatment due to cost, and weak cashflow through your accounts.

For the patient, a flexible 3dee loan can pay for treatment costs from £250 to $£ 25,000$ over six to sixty months on an interest free option or at very sensible and affordable interest rates. The process is simple, only basic non-intrusive information is required and 3dee provide a rapid response, so there's no delay in the start of treatment.

For the practice there is a real bonus in the fact that a 3 dee patient loan will be paid to the practice in advance, irrespective of the amount, at the start of the treatment.With a dedicated practice support service that includes provision of all the necessary paperwork, explanatory patient leaflets, promotional and practice marketing support and in-house training for your dental support team, offering the 3 dee option to your patients is made as easy as possible.

For more information on how 3 dee can make a positive impact on your cashflow and your patients' satisfaction, call 08452301324.

Reader response number 56

\section{Finance on-line}

MediFinance has launched a new on-line service to provide flexible finance for dentists. Based on the premise of simplicity, the new service offers finance options for anything related to the dental practice, from leasing and loans for dental equipment and practice refurbishment to personal arrangements for cars and property.

The difference in the service lies in the MediFinance promise of confirmation of the funds available to you within 24 hours. This is based on their Six Simple Questions application, available on-line at www.medifinance.co.uk. The company is dedicated to offering the best service in dental finance and because MediFinance is not compelled to use a single source of finance, they can negotiate with a number of different financial partners to obtain the best deal for customers.

\section{MediFinance invites any den- MEDIFinancet MediFinance invites any den-
tist seeking funds for new surgery equipment, computers, practice premises, refurbishment or cars to call 08006090069 or visit www.medifinance.co.uk for more information. \\ Reader response number 57}

\section{Dentists' \\ Provident}

The Dentists' Provident Society (DPS) is the UK's leading income protection provider for dentists, routinely providing the two most important protection measures that all dental practitioners need sickness and accident protection, and a share of the society's profits, receiving a lump sum upon retirement.

Established in 1908, DPS has over 13,000 members and assets of over $£ 130$ million. It enjoys the highest reputation within the profession and offers exceptional protection exclusively to qualified dentists throughout the UK and the Republic of Ireland.

DPS fully appreciates the difficulties likely to be faced by a dentist during a period of incapacity. With nearly 100 years' experience, they are able to design individual policies to suit the needs of individual dentists.

Dentists' Provident is delighted to be exhibiting at the 2006 BDA conference in Birmingham this May, where they will have their team on hand to answer any questions you may have regarding the income protection options available.

For more information about DPS, including how to become a member, call 02072222511 or visit stand 25 at the BDA conference.

Reader response number $\mathbf{5 8}$

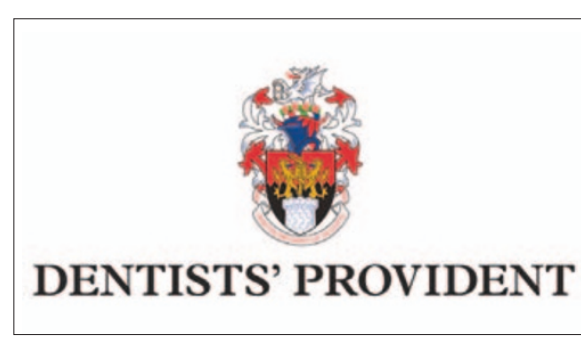

\section{Much more than money}

Medenta provides a diverse off the shelf and bespoke range of financial solutions for dental professionals, covering every aspect of business and personal finance. Although offering everything one would expect from a conventional finance company, it is providing the unexpected that marks Medenta out from the rest.

In particular, the $0 \%$ facility for patient fees is designed to help practices make more treatment increasingly accessible and affordable. With an ethos built firmly on the principles of quality advice, coaching and training, Medenta demonstrates its desire to offer much more than money by providing all that is needed to help dentists integrate this valuable tool into their businesses.

For more information please contact Margaret Gray at Medenta on 01294316559 or visit www.medenta.com. Reader response number 59

\section{DPAS dental plans}

DPAS is a payment collection agent and provider of dental insurance that supports practices in offering their own, independent practice-branded dental plans. Instrumental in the establishment and growth of private dental payment plans in the UK, the DPAS team are experts at supporting modern, forward thinking dental practices to offer a range of bespoke private dental payment plans under their own identity and control.The key elements of DPAS bespoke dental plans are choice, flexibility and operational freedom. At the cornerstone of their work is the desire to offer dentists the facility to run their practices exactly as they wish, relieved of the burden of payment administration and unnecessary complication.

Whatever your current situation and whatever the level of support you require, DPAS offers solutions specifically tailored to the needs of your practice. For further information call 01747870910 or visit www.dpas.co.uk.

Reader response number 60
DPAS Bespoke Dental Plans 


\section{Professional practice}

valuation

The Association of Service Providers to Dentists (ASPD) comprises accountants, independent financial advisers, banks, practice valuers, finance and leasing companies and solicitors with specialist expertise and proven track records of success in the provision of services to dentists and the dental industry. This wide sector experience makes them uniquely qualified to offer dentists informed, practical and objective guidance and advice.

Asset valuation is a key element for any business and when you need to know what your practice is worth, accuracy is essential. Whether you are taking on a partner, retiring, or using the business as collateral to finance expansion, an ASPD valuer is independent, thoroughly familiar with the market and has the knowledge to include intangibles such as goodwill and reputation in the final figure. Your valuation will be up to date and will take into account your practice's particular characteristics and the current state of the market.

An independent valuation is the starting point for all financial negotiations and the underlying factor that supports every practice's financial health. You can rely on the

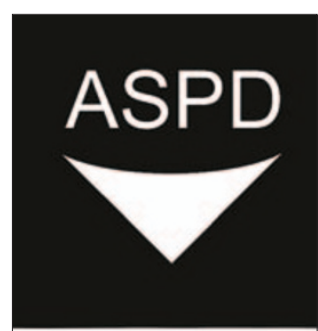

Association of Specialist Providers to Dentists skill, knowledge and objectivity of an ASPD valuer.

For more information call ASPD on 0800 458 6773, email info@aspd.co. uk or visit www.aspd.co.uk. Reader response number 62

\section{Plan for the future}

Practice Plan provides over 750 dental practices with their own unique private patient scheme that guarantees them a regular income, protects dentists' hourly rate, retains the practice identity and offers patients a greater choice. The unique, distinctive character of the client practices is never compromised and Practice Plan will work with you to achieve the type of plan best suited to your patients and your practice.

If you are considering a conversion to private practice or would like more information on your options in the current dental market, make sure you make Practice Plan the first stand you visit at the 2006 BDA conference in May. Practice Plan consultants have unrivalled knowledge and experience of the dental market and a justified reputation for delivering a quality product and the highest standards of care to a substantial and rapidly expanding client portfolio. They will be on hand to offer advice and guidance to anyone considering the step to private practice.

For more information about Practice Plan call 01691677966 or visit stand 30 at the 2006 BDA conference.

Reader response number 61

\section{Dental Practice Consultancy Service}

Dental Practice Consultancy Service (DPCS) is a new and exciting independent consultancy agency that offers its clients the skills of some of the most highly regarded practice sales agents in the UK. Their innovative approach, in-depth knowledge and wide experience are rapidly earning DPCS an enviable reputation and the respect of the entire industry.

DPCS consultants have been easing the financial burden for dental professionals since 1990 and with the formation of DPCS in 2000 they are now able to offer their dental clients bespoke financial schedules which reflect their specialist industry knowledge.

This knowledge includes practice valuations, sales and purchases; financial health checks and practice income analysis; and practice contractual agreements.

DPCS consultants are proud of their reputation for courteous, uniquely personal service and meticulous attention to detail. Whether working in the NHS or in private practice, DCPS is confident its services can be of benefit to all practising dentists. To find out more, visit www.dentalconsultancy.co.uk or call 08704443742.

Reader response number 63

\section{Save money with FIEA}

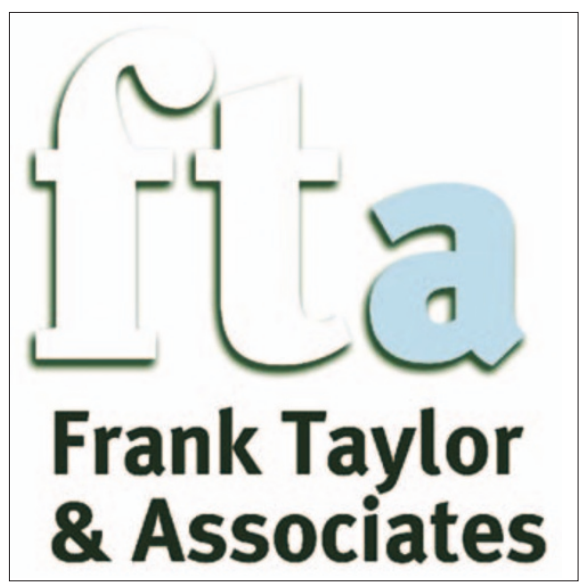

Frank Taylor \& Associates (FTEA) is the UK's leading practice broker and most respected practice valuer, with over 18 years experience in this specialist field. Dedicated to the needs of the dental profession, FTtA is pleased to inform customers that they can now save money by calling FTtA on their new Low Call number, 08456123434.

The Low Call number allows customers to call FTEA from a landline telephone anywhere in the United Kingdom for the cost of a local call. This new service provides customers with a cheaper option for contacting the company with any enquiries and assistance they may need before, during and after the sale of their practice.

FTEA offers a huge range of free advice over the telephone, informing dentists of important issues such as retirement planning. They also have extensive experience in helping and advising dentists considering converting to private practice. The new Low Call number makes all this experience easily accessible to any dentist wishing to seek advice on a wide range of financial issues.

For more information, call 08456123434 now to speak to Frank Taylor \&t Associates. Reader response number 64 